\title{
Morphological Characterization of Soursop (Annona muricata L.) Germplasm in Sri Lanka
}

\author{
S.M.P.C. Padmini, D.K.N.G. Pushpakumara ${ }^{1 *}$ and R. Samarasekera ${ }^{2}$ \\ Postgraduate Institute of Agriculture \\ University of Peradeniya \\ Sri Lanka
}

\begin{abstract}
Annona muricata $L$. is an underutilized fruit tree species in Sri Lanka,

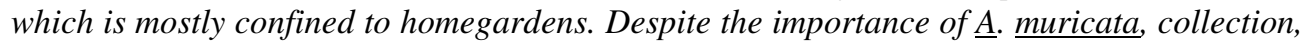
characterization and improvement of its germplasm is limited in Sri Lanka, hence hindered its effective conservation and utilization. Therefore, the objective of this research was to identify morphological variation of $\underline{A}$. muricata populations in Sri Lanka. Multistage Sampling Survey was conducted in homegardens of Anuradhapura, Polonnaruwa and Hambantota dictricts in the Dry zone, Puttalama and Kurunagala districts in the AIntermediate zone, and Kalutara and Gampaha districts in the Wet zone. Random representative samples were also collected from existing germplasm collections at three national research centers. Morphological variation of $\underline{A}$. muricata were observed on total of 315 samples collected from seven districts of three climatic zones and 133 samples collected from germplasm collections at three national research centers. Forty five morphological characters were recorded from 448 accesions and subjected to Principal Component Analysis (PCA) and Factor Analysis (FA), followed by Cluster Analysis. A dendrogram of evaluated characters showed nine distinguished clusters. Implications of findings are discussed in relation to utilization and conservation.
\end{abstract}

Keywords: Annona muricata, morphological variations, homegardens, factor analysis, cluster analysis

\section{INTRODUCTION}

Annona muricata L. of the family Annonaceae (commonly known as Sour sop, Katu anoda or Katu arrtha) is one of the world's most exquisite, but less studied fruit species in Sri Lanka. The fruits are consumed widely as fresh form and the other plant parts are also a source of medicinal and other industrial products such as beverages, wine, jellies, jam and fruit-butter preserves and pure (Gleye et al., 1997; Pinto et al., 2005; Abbo et al., 2006; Heenkenda et al., 2011). The fruits contain vitamins, minerals, bioactive chemical substances. The other plant parts also contain numerous amounts bioactive chemical substances such as acetogenins, alkaloids, terpens, flavonoids, cyclopeptide annomuricatin and oils (Roblot et al., 1993; Wu et al., 1995; Ming et al., 1998; Gleye et al., 1999; Pinto et al., 2005). These compounds are very useful medicines because some acetogenins have antitumoral, insecticidal, antibacterial, immuno-suppressant, pesticidal or antihelminthic properties (Kim et al., 1998; Yu et al., 1998). However, in Sri Lanka A. muricata is

Department of Crop Science, Faculty of Agriculture, University of Peradeniya, Peradeniya, Sri Lanka

Industrial Technology Institute, Bauddhaloka Mawatha, Colombo 7, Sri Lanka

Corresponding author: ngpkumara@pdn.ac.lk 
categorized as an underutilized fruit tree species (Heenkenda et al., 2011). Only a limited amount of researches has been conducted on Annona species in Sri Lanka (Thantirige, 2001; Heenkenda et al., 2011), though this species in general has high potential to diversify the farming system (Bowe and Haq, 2010).

Morphological characterization of a species is very useful in the separation of populations into different morphotypes and proper utilization of genetic resources in plant breeding programmes (Piyasundara et al., 2009). Better understanding of genetic diversity present and its distribution is essential for rational utilization of germplasm in crop improvement (Piyasundara et al., 2009). Study of plant genetic resources are also important to identify agrobiodiversity and this include primitive forms of cultivated plants, modern cultivars, ex situ collections and related wild species. Genetic diversity created in farmers' fields, homegardens over millennia (Upadhyaya et al., 2008). Genetic relationships between nine A. muricata accessions using RAPD markers have been reported in Venezuela (Brown, et al., 2003) where higher genetic variability has been reported according to the country of origin of plants. The objectives of the present research was identification of morphological variation of A. muricata population in homegardens and collection of germplasm centers in Sri Lanka

\section{MATERIALS AND METHODS}

\section{Data collection and sampling method for $A$. muricata trees}

Tree of A. muricata is found mainly in homegardens of many parts of Sri Lanka except in the higher elevations (Pinto et al., 2005; Anon, 2007) and four ex situ A. muricata gemplasm collections are located in Fruit Research Institute (FRI), Horana, Regional Agricultural Research and Development Centre (RARDC), Makadura, Horticultural Crop Research Institute (HORDI), Gannoruwa and Agricultural Research Station (ARS), Giradurukotte. Sampling of homegardens was done using the multistage sampling method to conduct the survey in large geographical area in the country. In order to increase the precision of sampling a large number of clusters were used as Thattil (1999) and Thattil and Samita, (2007) suggested. Sampling was carried out as shown in Fig.1.

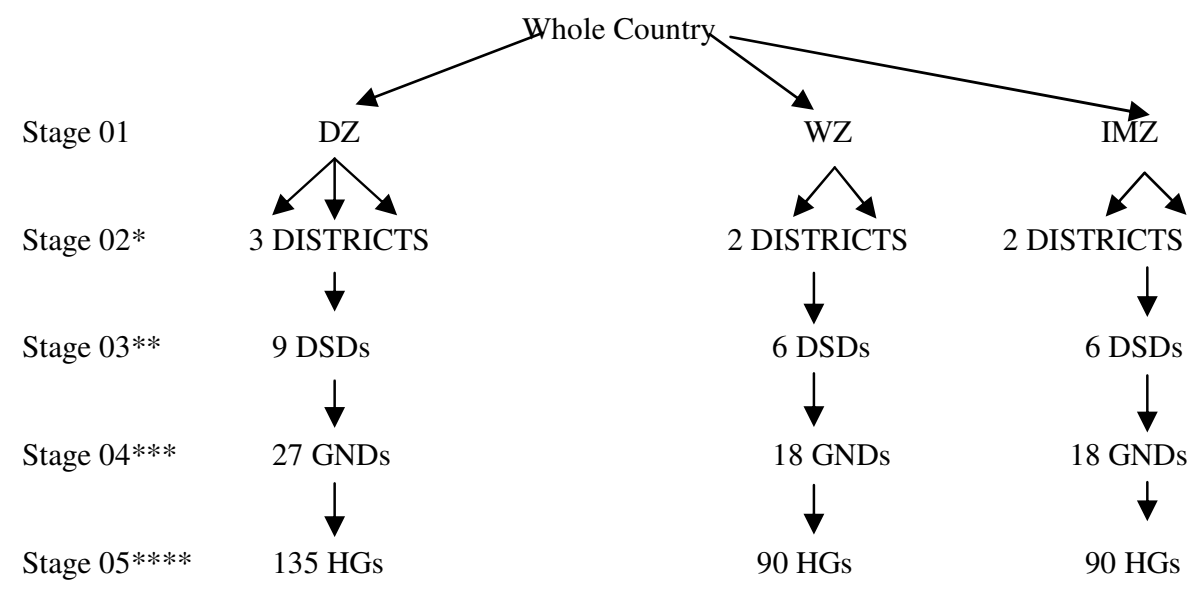

Fig. 1. Flow diagram of sample frame for A. muricata trees at homegardens. 
Note: * Number of districts depends on size of the major climate zones; ** within each District, three Divisional Secretariat Divisions (DSDs) were selected randomly; *** within each DSD, three Grama Niladari Divisions (GNDs) were selected randomly; **** within each GND, five Homegardens (HGs) were selected randomly (Thattil, 1999).

The three main climatic zones were used in the first stage whereas administrative districts were randomly selected in the second stage. The number of districts depends on size, homogeneity and heterogeneity of the climatic zones. Accordingly three districts from the dry zone (Anuradhapura, Polonnaruwa, and Hambantota), two districts from the wet zone (Kalutara and Gampaha) and two districts from the intermediate zone (Puttalama and Kurunagala) were selected. In the third stage, Divisional Secretariat Divisions (DSDs) were considered and three DSDs were selected randomly from each district. In the fourth stage Grama Niladari Divisions (GNDs) were considered and three GNDs were selected randomly from each DSD. At the fifth level A. muricata tree at homegardens (HGs) were considered for sample collection. Five homegardens were visited in each GND and A. muricata trees were selected randomly if there were more than one plant at the considered homegarden (as shown in Fig. 1). Distribution of sampling sites (DSDs of relevant districts) is given in Fig. 2.

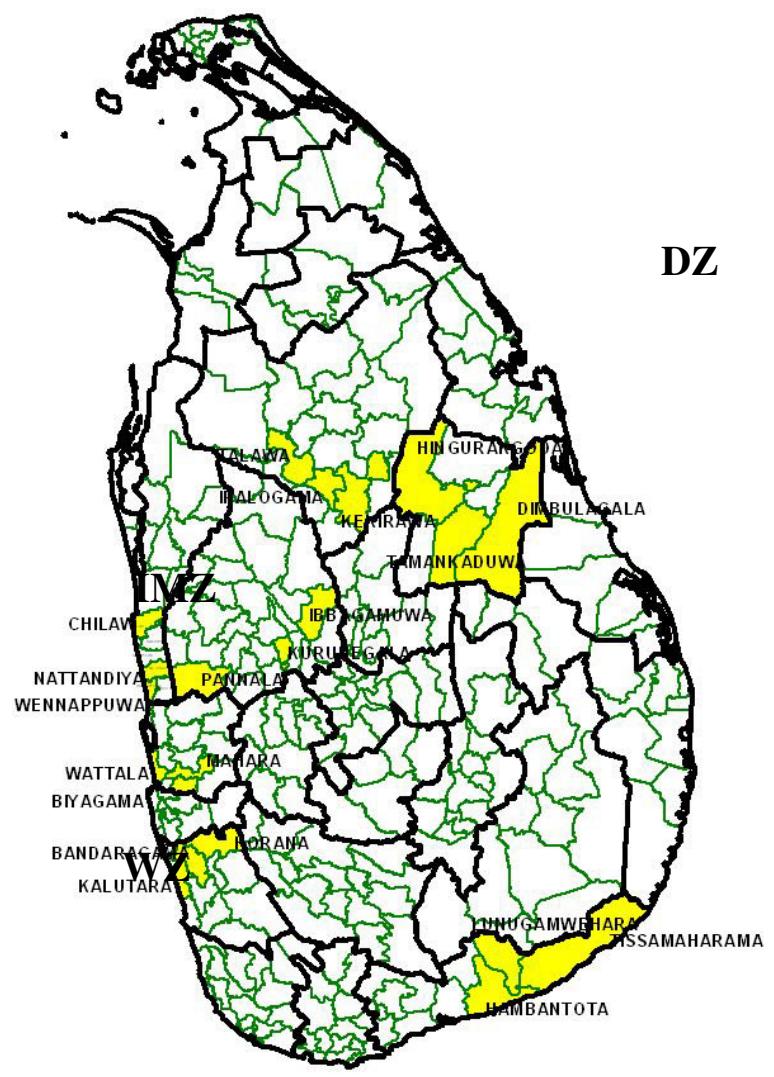

Fig. 2. Distribution of sampling sites (DSDs of selected districts) in Sri Lanka.

Since a descriptor list for A. muricata is not available, the descriptor list of A. cherimola Mill. (Cherimoya) compiled by the International Plant Genetic Resources Institute (IPGRI, 
2008) was used in this study. Accordingly, 45 morphological descriptors were identified and assessed. Fourteen quantitative characters were measured including leaf length, leaf width, petiole length, petal length, petal width, fruit length, fruit diameter, weight of ripe fruit, peduncle length, weight of all fresh seeds, number of seeds, weight of fresh seed, seed length and seed width. From each tree ten fully expanded and healthy leaves, ten flowers and ten well developed fruits were randomly selected for measurements of characters. Thirty one qualitative characters were categorized and measured (Table 1). Colour chart of Royal Horticulture Society (RHS) was used to identify parameters such as trunck colour, leaf colour, flower colour, exocarp color, pulp colour and seed colour. Resistance to abrasion was recorded by thumb friction. Pulp oxidation was observed by pale colour of the pulp five minutes after cutting the fruit. Tenacity of the seed in its epithelium was observed by cutting of seed and observing the seed coat and the firmness of epithelium by removing cotyledon from seed coat.

\section{Data analysis}

Non parametric data were converted to scales as proposed by IPGRI in descriptors for $A$. cherimola (IPGRI, 2008). A total of 315 samples were analysed from dry, wet and intermediate zones of the country and 133 samples were collected from four Germplasm Collecting Centers. Among 45 characters, 22 morphological characters did not show any variance in 448 accesions and accordingly removed from the analysis (Table 1 show such variables using asteric*), leaving only 23 characters to be used in the primary analysis. As per Table 1 leaf length, petiole length, petal length, petal width, weight of fresh seed, seed length and seed width were also removed from the analysis due to low coefficient of variation (below $25 \%$ of $\mathrm{CV}$, noted as **). Finally, only 15 characters were considered for analysis namely trunk colour, trunk ramification, suckering tendency, colour of young branches, leaf blade shape, average leaf width $[\mathrm{mm}]$, petal outer colour, location of fructification, fruit length $[\mathrm{mm}]$, fruit diameter $[\mathrm{mm}]$, weight of ripe fruit $[\mathrm{g}]$, peduncle length $[\mathrm{mm}]$, weight of all fresh seeds per fruit $[\mathrm{g}]$, number of seeds, pulp taste (Table 1).

Principal Component Analysis (PCA) and Factor Analysis (FA) were carried out using average values of descriptors. The results were used for cluster analysis. The analysis was conducted using Statistical Analysis System (SAS) for Windows Version 8e (Anon, 1999). The PCA and FA were used conducted for total data set and for data from districts and germplasm collecting centers, separately. Eigen values greater than 1.00 and cumulative proportion of variation explained were used to identify number of principal components (Thattil and Samita, 2007). The magnitudes of the component coefficients in Eigen vectors were used to measure the importance of each character to the particular principal component. Cluster analysis is the partitioning of a set of objects into groups so that objects within a group are similar and objects in different groups are dissimilar. It is efficient in grouping objects with similar characters (Hodgkin et al., 1995). The analysis was performed using the cluster procedure (method=average linkage) and the dendrogram with the tree procedure of SAS. Previous studies have shown that the average linkage method was used by many researchers in cluster analysis studies (Piyasiri et al., 2001; Ruckshanthi et al., 2002; Piyasundara et al., 2009). Clusters were defined based on their unique characters. In order to identify the relationship of accessions, they were plotted using variables (i.e. fruit weight vs. number of seeds in the fruit) as shown in Fig. 3 Fruit weight / number of seeds ratio was to identify clusters. Correlations among characters were identified using two dimensional plotting of factors. 
Table 1. Variation of quantitative and qualitative characters measured and used in the analysis.

\begin{tabular}{|c|c|c|c|}
\hline Quantitative Characters & Mean & SD & $\mathrm{CV}$ \\
\hline Average Leaf width [mm] & 51.46 & 12.87 & 25.01 \\
\hline Fruit length [mm] & 157.16 & 42.23 & 26.87 \\
\hline Fruit diameter $[\mathrm{mm}]$ & 109.12 & 29.05 & 26.62 \\
\hline Weight of ripe fruit $[\mathrm{g}]$ & 509.72 & 480.77 & 94.32 \\
\hline Peduncle length [mm] & 34.83 & 16.98 & 48.76 \\
\hline Weight of all fresh seeds per fruit $[\mathrm{g}]$ & 12.75 & 7.46 & 58.51 \\
\hline Number of seeds & 44.76 & 23.19 & 51.80 \\
\hline$* *$ Average Leaf length $[\mathrm{mm}]$ & 135 & 17.47 & 12.94 \\
\hline **Petiole length $[\mathrm{mm}]$ & 8.08 & 1.73 & 21.46 \\
\hline$* *$ Petal length $[\mathrm{mm}]$ & 41.69 & 6.01 & 14.41 \\
\hline$* *$ Petal width $[\mathrm{mm}]$ & 36.25 & 4.94 & 13.63 \\
\hline$* *$ Weight of fresh seed $[\mathrm{g}]$ & 0.28 & 0.05 & 16.79 \\
\hline$* *$ Seed length $[\mathrm{mm}]$ & 14 & 1.89 & 13.50 \\
\hline$* *$ Seed width $[\mathrm{mm}]$ & 8.27 & 1.34 & 16.19 \\
\hline Qualitative Characters & \multicolumn{3}{|c|}{ Observed variation } \\
\hline Trunk colour & \multicolumn{3}{|c|}{$\begin{array}{l}1 \text { Light grey (0\%), } 2 \text { Grey }(77 \%), 3 \text { Dark } \\
\text { grey }(23 \%), 4 \text { Other }(0 \%)\end{array}$} \\
\hline Trunk ramification & \multicolumn{3}{|c|}{$\begin{array}{l}1 \text { One branch }(56 \%), 2 \text { Two }(26 \%), 3 \text { Three } \\
\text { or more }(18 \%)\end{array}$} \\
\hline Suckering tendency: number of suckers & \multicolumn{3}{|c|}{$\begin{array}{l}0 \text { Absent }(83.1 \%), 1 \leq 5 \text { suckers }(16 \%), 2>5 \\
\text { suckers }(0.9 \%)\end{array}$} \\
\hline Colour of young branches & \multicolumn{3}{|c|}{$\begin{array}{l}1 \text { Light green }(94 \%), 2 \text { Green }(6 \%), 3 \text { Dark } \\
\text { green }(0 \%) \text {, }\end{array}$} \\
\hline Leaf blade shape & \multicolumn{3}{|c|}{$\begin{array}{l}1 \text { Ovate }(15 \%), 2 \text { Elliptic }(0 \%), 3 \text { Obovate } \\
(85 \%), 4 \text { Lanceolate }(0 \%), 5 \text { Other }(0 \%)\end{array}$} \\
\hline Petal outer colour & \multicolumn{3}{|c|}{$\begin{array}{l}1 \text { Cream }(9 \%), 2 \text { Yellow }(91 \%), 3 \text { Green } \\
(0 \%), 4 \text { Brown }(0 \%), 5 \text { Other }(0 \%)\end{array}$} \\
\hline Location of fructification & \multicolumn{3}{|c|}{$\begin{array}{l}1 \text { Base }(17 \%), 2 \text { Middle (66\%), } 3 \text { Top of the } \\
\text { crown }(17 \%)\end{array}$} \\
\hline Pulp taste & \multicolumn{3}{|c|}{$3 \mathrm{Bad}(0 \%), 5$ Average (4\%), 7 Good (96\%) } \\
\hline *Pubescence of young branches & \multicolumn{3}{|c|}{0 Absent $(100 \%), 1$ Present $(0 \%)$} \\
\hline *Shape of leaf base & \multicolumn{3}{|c|}{$\begin{array}{l}1 \text { Acute }(100 \%), 2 \text { Rounded }(0 \%), 3 \text { Obtuse } \\
(0 \%), 4 \text { Cordate }(0 \%)\end{array}$} \\
\hline *Shape of leaf apex & \multicolumn{3}{|c|}{$\begin{array}{l}1 \text { Acute }(100 \%), 2 \text { Rounded }(0 \%), 3 \\
\text { Acuminate }(0 \%)\end{array}$} \\
\hline *Pubescence of leaf & \multicolumn{3}{|c|}{0 Absent (100\%), 1 Present $(0 \%)$} \\
\hline
\end{tabular}


*Colour of mature leaves

*Colour of young leaves

*Leaf margin

*Leaf blade venation

*Colour of the internal petal base

*Petal pubescence

*Sepal pubescence

*Fruit shape

*Uniformity in fruit size

*Fruit symmetry

*Exocarp type

*Exocarp colour

*Resistance to abrasion

*Pulp colour

*Pulp texture

*Pulp fibre content

*Pulp oxidation

Seed coat colour

*

Tenacity of the seed in its epithelium
1 Light green (0\%), 2 Green $(0 \%)$,

3 Greyish green (0\%), 4 Dark green (100\%), 5 Other $(0 \%)$

1 Light green (100\%), 2 Green (0\%), 3 Dark (0\%), 4 Other $(0 \%)$

1 Entire (100\%), 2 Undulate (0\%)

3 Submerged (0\%), 5 Intermediate (100\%), 7

Raised (0\%)

1 Pink (0\%), 2 Light red (0\%), 3 Dark red

(0\%), 4 Cream $(100 \%)$

0 Absent (100\%), 1 Present (0\%)

0 Absent (100\%), 1 Present (0\%)

1 Round $(0 \%), 2$ Oblate $(0 \%), 3$ Cordate

$(0 \%), 4$ Broadly cordate $(100 \%), 5$ Oval

$(0 \%), 6$ Other $(0 \%)$

0 No $(100 \%), 1$ Yes $(0 \%)$

0 No (100\%), 1 Yes $(0 \%)$

1 smooth (0\%), 1 slight depressions (0\%), 3

small protrusions $(0 \%), 4$ medium

protrusions (100\%), 5 large protrusions

$(0 \%), 6$ Other type $(0 \%)$

1 Light green (0\%), 2 Green (1\%), 3 Dark

green $(0 \%), 4$ Yellowish green $(99 \%), 5$

Yellow (0\%), 6 Brownish green $(0 \%), 7$

Brown $(0 \%), 8$ Other $(0 \%)$

0 No $(0 \%), 1$ Yes $(100 \%)$

1 White (100\%), 2 Cream (0\%), 3 Other

$(0 \%)$

1 Watery (100\%), 2 Creamy (0\%), 3

Granular (0\%), 4 Hard (0\%), 5 Hard areas in the pulp (0\%), 6 Other $(0 \%)$

0 Absent (0\%), 1 Low (0\%), 2 High (100\%)

1 Poorly (0\%), 2 Oxidized (100\%), 3 Very oxidized $(0 \%)$

1 Grey (1\%), 2 Dark brown (99\%), 3 Black,

1 Cloaked (100\%), 2 Semi-cloaked (0\%), 3 Loose (0\%)

Note:The highlighted (bold) 15 characters ( 7 quantitative and 8 qualitative characters) were considered for PCA and FA analysis and other morphological characters were removed due to lack of variation among accessions. (* indicated characters with no variation. ** indicated characters with low CV) 


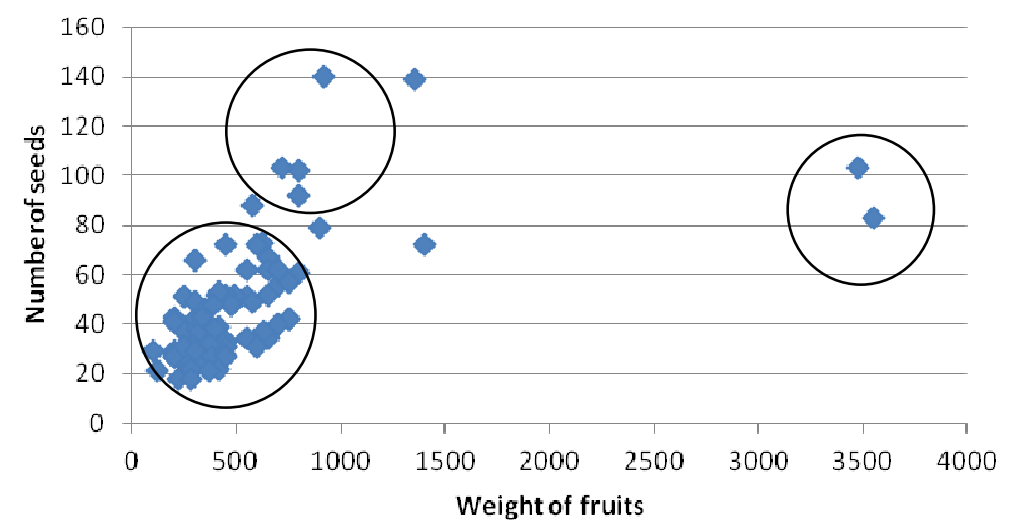

Fig. 3. Relationship between fruit weight and number of seeds of fruits in germplasm centers and seven districts

\section{RESULTS AND DISCUSSION}

The first five principal components explained 69\%, 79\%, and 76\% of the accumulated variance of the total sampled germplasm collections (Table 2), samples collected from germplasm collecting centre (Table 3 ) and from seven districts (Table 4), respectively.

Table 2. Factor loading, eigen values and percentage of total (standardized) population variance explained by five factor model of 15 morphological characters

\begin{tabular}{lcccccc}
\hline Morphological characters & $\begin{array}{c}\text { Factor } \\
\mathbf{1}\end{array}$ & $\begin{array}{c}\text { Factor } \\
\mathbf{2}\end{array}$ & $\begin{array}{c}\text { Factor } \\
\mathbf{3}\end{array}$ & $\begin{array}{c}\text { Factor } \\
\mathbf{4}\end{array}$ & $\begin{array}{c}\text { Factor } \\
\mathbf{5}\end{array}$ & $\begin{array}{c}\text { Comm } \\
\text { unality }\end{array}$ \\
\hline Trunk colour & -0.408 & $\mathbf{0 . 7 8 9}$ & 0.136 & -0.008 & -0.039 & 0.80 \\
\hline Trunk ramification & -0.100 & -0.263 & $\mathbf{0 . 7 0 9}$ & -0.031 & -0.001 & 0.58 \\
\hline Suckering tendency & 0.112 & -0.222 & $\mathbf{0 . 7 4 9}$ & 0.299 & 0.077 & 0.71 \\
\hline Colour of young branches & -0.096 & -0.285 & $\mathbf{- 0 . 4 4 7}$ & 0.206 & 0.182 & 0.36 \\
\hline Leaf blade shape & 0.339 & $\mathbf{- 0 . 6 3 0}$ & 0.127 & 0.107 & 0.034 & 0.54 \\
\hline Average Leaf width [mm & 0.369 & $\mathbf{- 0 . 7 7 6}$ & 0.077 & 0.151 & -0.017 & 0.76 \\
\hline Petal outer colour & -0.419 & -0.087 & 0.038 & $-\mathbf{0 . 5 1 8}$ & -0.113 & 0.46 \\
\hline Location of fructification & -0.056 & 0.173 & -0.246 & $\mathbf{0 . 7 5 1}$ & -0.346 & 0.77 \\
\hline Fruit length [mm & $\mathbf{0 . 6 5 9}$ & 0.593 & 0.133 & -0.029 & -0.002 \\
\hline Fruit diameter [mm] & $\mathbf{0 . 7 0 2}$ & 0.358 & 0.115 & -0.091 & 0.119 & 0.80 \\
\hline Weight of ripe fruit [g] & $\mathbf{0 . 7 4 2}$ & 0.312 & 0.017 & -0.019 & 0.113 & 0.65 \\
\hline Peduncle length [mm] & -0.389 & $\mathbf{0 . 5 8 9}$ & 0.339 & 0.264 & -0.124 & 0.66 \\
\hline Seed weight per fruit [g] & $\mathbf{0 . 9 0 5}$ & 0.075 & -0.055 & -0.049 & -0.068 & 0.83 \\
\hline Number of seeds & $\mathbf{0 . 8 7 6}$ & 0.085 & -0.083 & -0.026 & -0.164 \\
\hline Pulp taste & -0.099 & 0.194 & -0.050 & 0.198 & $\mathbf{0 . 8 9 3}$ & 0.80 \\
\hline Eigen values & 3.86 & 2.83 & 1.53 & 1.12 & 1.05 & 0.88 \\
\hline $\begin{array}{l}\text { Total population Variance } \\
\text { explained (\%) }\end{array}$ & 26 & 19 & 10 & 7 & 7 & \\
\hline $\begin{array}{l}\text { Cumulative total population } \\
\text { Variance explained (\%) }\end{array}$ & 26 & 45 & 55 & 62 & 69 & \\
\hline
\end{tabular}

Note: Highlighted values of each column represented selected characters of each principal component 
Table 3. Eigen values and percentage of total (standardized) population variance explained by five factor model of $\mathbf{1 5}$ morphological characters for germplasm collected from germplasm collecting centers.

\begin{tabular}{lccccc}
\hline Factor & Factor & Factor & Factor & Factor & Factor \\
& $\mathbf{1}$ & $\mathbf{2}$ & $\mathbf{3}$ & $\mathbf{5}$ & \\
\hline Eigen value & 4.227 & 1.929 & 1.532 & 1.478 & 1.097 \\
$\begin{array}{l}\text { Total population Variance } \\
\text { explained (\%) }\end{array}$ & 33 & 15 & 13 & 11 & 8 \\
$\begin{array}{l}\text { Cumulative Total } \\
\text { population Variance } \\
\text { explained (\%) }\end{array}$ & 33 & 48 & 60 & 71 & 79 \\
\hline
\end{tabular}

In five factor model each character contributed a high percentage variation. The first principal component explained $26 \%$ of the variation and was associated with fruit characters such as length, diameter and weight of ripe fruit, weight and number of seeds per fruit. The second principal component explained $19 \%$ of the variation and was associated with trunk colour, leaf blade shape, average leaf width and peduncle length. The third principal component explained $10 \%$ of the variation and was associated trunk ramification, suckering tendency and colour of young branches. The $4^{\text {th }}$ and $5^{\text {th }}$ principal components explained variation $7 \%$ each. The $4^{\text {th }}$ principal component was associated with petal outer colour and location of ramification whereas $5^{\text {th }}$ principal component was associated with pulp taste (Table 2).

Table 4. Eigen values and percentage of total (standardized) population variance explained by five factor model of $\mathbf{1 5}$ morphological characters for germplasm collected from seven districts.

\begin{tabular}{lccccc}
\hline Factor & Factor1 & Factor2 & Factor3 & Factor4 & Factor5 \\
\hline Eigen value & 3.706 & 3.194 & 1.638 & 1.061 & 1.041 \\
$\begin{array}{l}\text { Total population } \\
\begin{array}{l}\text { Variance explained (\%) } \\
\text { Cumulative Total } \\
\text { population Variance } \\
\text { explained (\%) }\end{array}\end{array}$ & 26 & 23 & 12 & 8 & 7 \\
\hline
\end{tabular}

The characters can be used in the A. muricata improvement programmes as the knowledge of correlation among characters is useful in designing an effective breeding programme (Asudi et al., 2010). Fruits collected from Giradurakotte Germplasm collecting center contain large fruit weight $(3.355 \mathrm{~kg}$ and $3.48 \mathrm{~kg})$ and fruits which contain less number of seeds are important for agricultural industries. These germplasms should be conserved and should be promoted for utilization. Fruits contain higher number of seed and low fruit weight can be utilized for future breeding programmes and need attention to conservation of those germplasm too. 


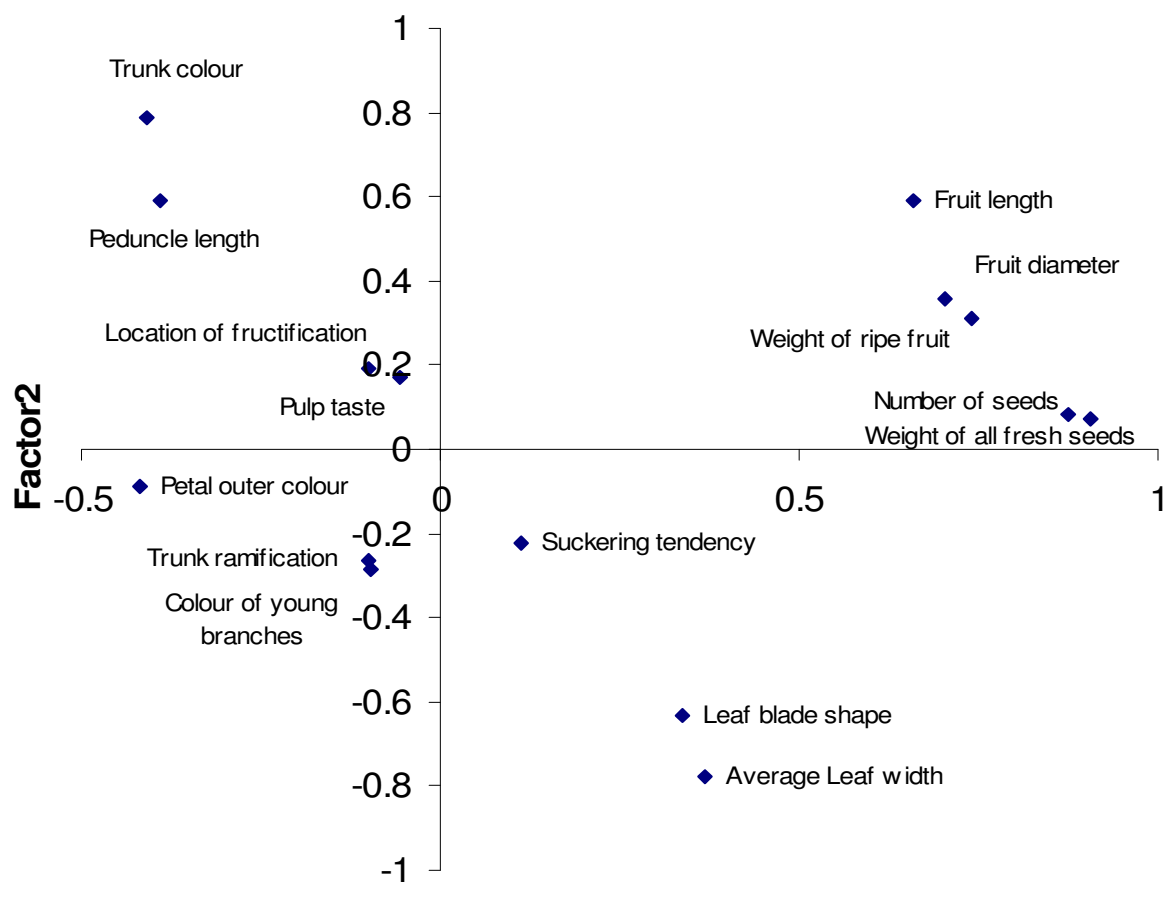

Factor1

Fig. 4. Correlation among characters associated with first and second factor competent

\section{Cluster analysis}

The germplasm of A. muricata was grouped into nine distinct clusters at 1.00 linkage distance with each cluster containing accessions that are morphologically similar (Fig. 5). Distinct characters were indicated in Table 5. This indicates that the present collection probably contain duplicates. Molecular and chemical characterization of these individuals along with morphological characterization will provide the basis for utilization of fruits and conservation of individuals. 


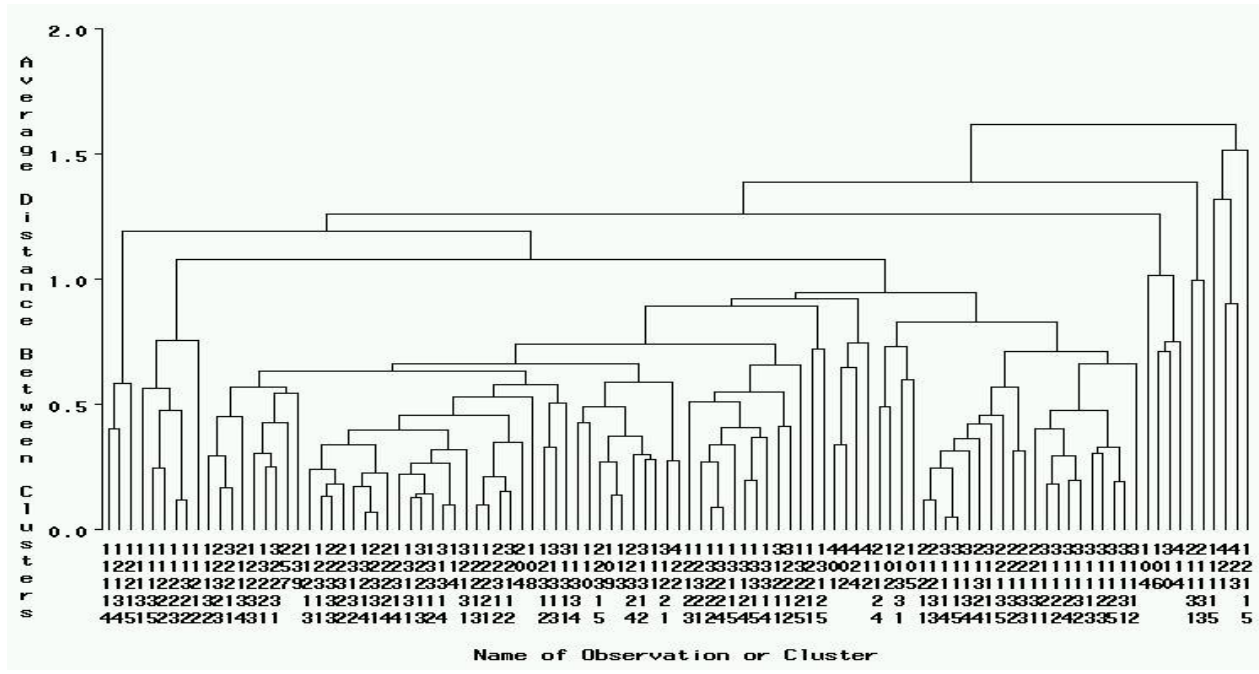

Fig. 5. Dendrogram obtained from average linkage cluster analysis for all accessions

Table 5. Cluster composition of all accessions.

\begin{tabular}{|c|c|}
\hline Cluster & Accessions and distinct character \\
\hline 1 & $\begin{array}{l}\text { Cluster } 1 \text { is consisted of accession } 12115 \text { from Hambantota district with highest number } \\
\text { of seeds and } 15 \% \text { seed / fruit weight ratio. This accession is not consumed and need } \\
\text { chemical analysis because owners stated that once consumed people get fever and } \\
\text { allergy conditions. }\end{array}$ \\
\hline 2 & $\begin{array}{l}\text { Cluster } 2 \text { comprises two accessions, } 423 \text { and } 421 \text { from Giradurukotte Germplasm } \\
\text { collecting center. Those fruits are very large } 3.355 \mathrm{~kg} \text { and } 3.48 \mathrm{~kg} \text {. Seed / fruit weight } \\
\text { ratio is } 3-6 \% \text {. The Officer in Charge of the Germplasm Center of Giradurukotte } \\
\text { informed that those germplasm were collected in the year } 1996 \text { from the dry zone of Sri } \\
\text { Lanka. These accessions can be used for the future breeding programs. }\end{array}$ \\
\hline 3 & $\begin{array}{l}\text { Cluster } 3 \text { comprises only one accession, } 11115 \text { which was collected from Kekirawa DS } \\
\text { division of Anuradhapura district. It consists of medium sized fruit and seed / fruit } \\
\text { weight ratio is } 12 \% \text {. }\end{array}$ \\
\hline 4 & $\begin{array}{l}\text { Cluster } 4 \text { comprises three accessions } 21133,21131 \text {. The plants located in the wet zone } \\
\text { areas of Gampaha district, Biyagama DS division, Meegaswaththa GS division. Small } \\
\text { size fruit, seed / fruit weight ratio is } 8-9 \% \text {. }\end{array}$ \\
\hline 5 & $\begin{array}{l}\text { Cluster } 5 \text { comprises the accessions 106, 310, } 414 \text { from germplasm collections centers at } \\
\text { HORDI, Gannoruwa, Fruit Research Institute, Horana and Giradurukotte. Medium size } \\
\text { fruits, seed / fruit weight ratio is 5-14\%. }\end{array}$ \\
\hline 6 & $\begin{array}{l}\text { Cluster } 6 \text { comprises the accession 104, from germplasm collections centers in HORDI, } \\
\text { Gannoruwa. Fruit is medium, seed / fruit weight ratio is } 9 \% \text {. }\end{array}$ \\
\hline 7 & Cluster 7 comprises all other accessions which did not group in to other clusters. \\
\hline 8 & $\begin{array}{l}\text { Cluster } 8 \text { comprises accessions } 11212,11322,11223,11222,11131 \text {, and consists of } \\
\text { small size fruits in dry zone located in Anuradhapura district, seed / fruit weight ratio is } \\
10-29 \% \text {. }\end{array}$ \\
\hline 9 & $\begin{array}{l}\text { Cluster } 9 \text { comprises accessions } 11114,12134,12215 \text { those bears small size fruits in dry } \\
\text { zone, districts where fruit weight to seed ratio is low }(10-14 \%) \text {. }\end{array}$ \\
\hline
\end{tabular}




\section{CONCLUSIONS}

Results of the study revealed that five principle components from 15 characters explained $69 \%$ of total variability of A. muricata germplasm. Cluster analysis identified nine clusters with unique characters. Most prominent character is fruit weight to seed ratio. This factor is important in utilization of the fruit. Therefore, clusters which have higher and lower fruit weight to seed ratio are important to promote for utilization of breeding programmes and conservation of germplasms.

\section{ACKNOWLEDGEMENT}

Authors gratefully acknowledge the Sri Lanka Council for Agricultural Research Policy (SLCARP) and Horticultural Crop Research and Development Institute (HORDI) of Department of Agriculture for their support extended to complete this research.

\section{REFERENCES}

Abbo, E.S., Olurin, T.O. and Odeyemi, G. (2006). Studies on the storage stability of sour sop (Annona muricata L.) juice. African Journal of Biotechnology. 5(19), 1808-1812.

Anon (1999). Statistical Analysis System (SAS) for windows version 8e. SAS Institute, USA.

Anon (2007). Annual Report of exploration, collection, conservation and characterization of underutilized fruit species. Department of Agriculture, Sri Lanka.

Asudi, G.O., Obwara, F.K ., Riberia, F.K., Nyende, A.B., Ateka, E.M., Wamocho, L. S., Shitanda, D. and Onyango, A. (2010). Morphological diversity of Kenyan papaya germplam. African Journal of Biotechnology. 9(51), 8754-8762.

Bowe, C. and Haq, N. (2010). Quantify the global environmental niche and underutilized tropical fruit tree (Tamarindus indica) using herbarium records. Agriculture, Ecosystems and Environment. 139, 51-58.

Brown, J., Laurentin, H. and Davila, M. (2003). Genetic relationships between nine A. muricata accessions using RAPD markers. Fruits. 58, 255-259.

Gleye, C., Laurens, A., Hocquemiller, R., Laprevote, O., Serani, L. and Cave, A. (1997). Cohibins A and B, acetogenins from roots of Annona muricata. Phytochemistry. 44(8), 1541-1545.

Gleye, C., Laurens, A., Laprevote, O., Serani, L. and Hocquemiller, R. (1999), Isolation and structure elucidation of sabadelin, an acetogenin from roots of Annona muricata. Phytochemistry. 52, 1403-1408.

Heenkenda, H.M.S., Pushpakumara, D.K.N.G., Ranil, R.H.G. and Thantirige, M.K. (2011). Chapter 9: Annona, Annona species. In: Pushpakumara, D.K.N.G., Gunasena, H.P.M. and Singh, V.P.(eds) Underutilized fruit trees in Sri Lanka. Volume 2. World Agroforestry Centre, South Asia Office, New Delhi, India. pp.158-182. 
Hodgkin, T., Brown, A.H.D., Hintum, T.J.L. and Morales, E.A.V. (1995). Core collections of plant genetic resources. John Wiley \& Sons, UK.

IPGRI (2008). Descriptors for cherimoya. International Plant Genetic Resource Institute, Italy.

Kim, G.S., Zeng, L., Alali, F., Rogers, L.L., Wu, F.E., Sastrodihardjo, S. and McLaughlin, J.L.(1998). Muricoreacin and murihexocin C, monotetrahydrofuran acetogenins, from the leaves of Annona muricata. Phytochemistry. 49(2), 565-571.

Ming, L.C., Hua, T.N., Lan, Z.H., Qing, M., Jiang, H.X., Neng, H.Y. and Jun, Z., (1998). Cyclopeptide from the seeds of Annona muricata. Phytochemistry. 48(3), 555-556.

Pinto, A.C.deQ., Cordeiro, M.C.R., Andrade, S.R.M.de, Ferreira, F.R., Filgueiras, H.A.deC., Alves, R.E. and Kinpara, D.I. (2005). Monograph of Annona species. International Centre for Underutilised Crops, UK.

Piyasiri, C., Pushpakumara, D.K.N.G. and Thattil, R.O. (2001). Classification and Characterization of Abelmoschus esculentus (L.) Monech (Okra) germplasm using multivariate techniques. Sri Lankan Journal of Applied Statistics. 2, 41-52.

Piyasundara, J.H.N., Gunasekare, M.T.K. and Wickramasinghe, I.P. (2009). Characterization of tea (Camellia sinensis L.) germplasm in Sri Lanka using morphological descriptors. Sri Lanka Journal of Tea Science. 74(1), 31-39.

Roblot, F., Laugel, T., Lebeuf, M., Cave, A. and Laprevote, O. (1993), Two acetogenins from Annona muricata seeds. Phytochemistry. 3(1), 281-285.

Ruckshanthi, J.P.D., Pushpakumara, D.K.N.G., Perera, A.L.T. and Muhunthan, R. (2002). Morphological and genetic (RAPDs) characterization of Munronia pinnata (Meliaceae). Tropical Agriculture Research. 14, 11-21.

Thantirige, M.K. (2001). Effects of artificial pollination on fruit set in sour sop (Annona muricata L.). Annals of the Sri Lanka Department of Agriculture. 3, 265-273.

Thattil, R.O. (1999). Handbook on survey design and analysis. Postgraduate Institute of Agriculture, Sri Lanka, pp. 1-123.

Thattil, R.O. and Samita, S. (2007). Multivariate methods. University of Peradeniya, Peradeniya, Sri Lanka, pp. 1-55.

Upadhyaya, H.D., Gowda, C.L.L. and Sastry, D.V.S.S.R. (2008). Plant genetic resources management: collection, characterization, conservation and utilization. SAT eJournal. 6, 115 .

Wu, F.E., Zeng, L., Gu, Z.M., Zhao, G.X., Zhang, Y., Schwedler, J.T. and McLaughlin, J.L., (1995). Muricatocins A and B, two new bioactive monotetrahydrofuran annonaceous acetogenins from the leaves of Annona muricata. Journal of Natural Products. 58(6), 902908. 
Padmini et al.

Yakandawala, D.M.D. and Rubasinhge, S.C.K. (2003). Re-evaluation of species limits of Hortonia ( Monimiaceae) based on empirical methods. Ceylon Journal of Science (Biological Sciences). 31, 13-28.

Yu, J.G., Gui, H.Q., Luo, X.Z. and Sun, L. (1998). Murihexol, a linear acetogenin from Annona muricata. Phytochemistry. 49(6),1689-1692. 